\title{
Biorregulador e pré-condicionamento osmótico na germinação de sementes e no crescimento inicial da muda de carobinha (Jacaranda decurrens subsp. symmetrifoliolata Farias \& Proença) - Bignoniaceae
}

\author{
KISSMANN, C. ${ }^{1}$; SCALON, S.P.Q. ${ }^{2}$; SCALON FILHO, H. ${ }^{3}$; VIEIRA, M.C. ${ }^{2}$ \\ ${ }^{1}$ Departamento de Botânica, Universidade Estadual Paulista (UNESP), IB, Avenida 24-A, 1515, CEP: 13506-900, \\ Rio Claro-Brasil *camilakissmann@gmail.com ${ }^{2}$ Faculdade de Ciências Agrárias, Universidade Federal da \\ Grande Dourados, Rodovia Dourados - Itahum, Km12, CEP: 79804970, Dourados-Brasil ${ }^{3}$ Universidade Estadual \\ de Mato Grosso do Sul (UEMS), Rodovia Aquidauana/CERA - Km12, CEP: 79800-000, Aquidauana-Brasil
}

\begin{abstract}
RESUMO: O objetivo deste trabalho foi avaliar o efeito de tratamentos pré-germinativos na emergência das plantas e no crescimento inicial das mudas de Jacaranda decurrens subsp. symmetrifoliolata Farias \& Proença. Foram realizados dois experimentos. No primeiro, as sementes, separadas em claras e escuras, foram submetidas aos tratamentos pré-germinativos: 1) $\mathrm{KNO}_{3}$ (20000 mg L-1); 2) ácido giberélico $\left(\mathrm{GA}_{3}\right) 50 \mathrm{mg} \mathrm{L}^{-1}$, 3) $\mathrm{GA}_{3} 100 \mathrm{mg} \mathrm{L}^{-1}$ 4) $\mathrm{GA}_{3} 200 \mathrm{mg} \mathrm{L}^{-1}$; 5)

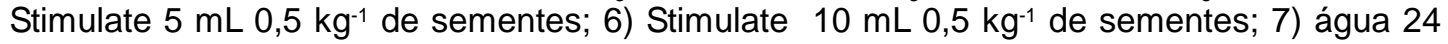
horas; 8) testemunha. A semeadura foi realizada em bandejas de células preenchidas com substrato terra + substrato comercial. Os cinco melhores tratamentos foram selecionados para avaliação do crescimento da muda. As plantas com 120 dias de idade provenientes dos seguintes

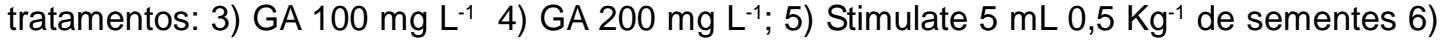

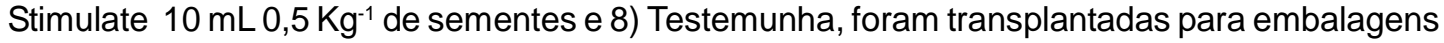
de plástico de $3 \mathrm{Kg}$ com substrato terra + areia + cama-de-frango (1:1:1 - v:v), mantidas em sombreamento de $50 \%$ e avaliadas aos 70,130, 170 e 210 dias após o transplante. Em geral, as sementes claras apresentaram maior germinabilidade e índice de velocidade de germinação (IVG) em relação às sementes escuras. Entretanto, as plantas provenientes dessas sementes apresentaram menor crescimento do que as plantas provenientes das sementes escuras. No segundo experimento as sementes foram pré-embebidas em solução de: 1) PEG 6000 (-1,0 $\mathrm{MPa})$; 2) PEG $\left.6000(-1,0 \mathrm{MPa})+\mathrm{KNO}_{3}\left(20000 \mathrm{mg} \mathrm{L}^{-1}\right)(-1,0 \mathrm{MPa}) ; 3\right) \mathrm{KNO}_{3}\left(20000 \mathrm{mg} \mathrm{L}^{-1}\right)(-1,0$ $\mathrm{MPa}$; 4) Água e 5) água deionizada, e incubadas em BOD a $10^{\circ} \mathrm{C}$ e $20^{\circ} \mathrm{C}$ durante 0 (controle), 6 , 12 e 24 horas. Após esses períodos elas foram secas em ambiente de laboratório até atingirem a massa apresentada antes do condicionamento e, posteriormente, incubadas em BOD a 20$30^{\circ} \mathrm{C}$ com $8 \mathrm{~h}$ escuro e $12 \mathrm{~h}$ de luz. Os tratamentos pré-germinativos não interferiram na vitalidade e no vigor das sementes osmocondicionadas por até 12 horas. Não houve diferença entre as temperaturas de 10 e $20^{\circ} \mathrm{C}$ para germinabilidade (60 \%) e IVG, porém a temperatura de $10^{\circ} \mathrm{C}$ originou plântulas com maior massa fresca $(95,7 \mathrm{mg})$ e comprimento médio de raiz $(3,2 \mathrm{~cm})$ e de parte aérea $(2,6 \mathrm{~cm})$. O osmocondicionamento por 24 horas causou redução na qualidade das sementes e vigor das plântulas.
\end{abstract}

Palavras-chave: bioestimulante, giberelina, osmocondicionamento, $\mathrm{PEG} 6000, \mathrm{KNO}_{3}$

ABSTRACT: Bioregulator and priming on seed germination and initial growth of "carobinha" (Jacaranda decurrens subsp. symmetrifoliolata Farias \& Proença Bignoniaceae) seedlings. The aim of this work was to evaluate the effect of pregerminative treatments on the emergence and initial growth of Jacaranda decurrens subsp. symmetrifoliolata Farias \& Proença seedlings. Two experiments were carried out. In the first experiment, seeds were separated into light and dark seeds and were subjected to the following pregerminative treatments: 1) $\mathrm{KNO}_{3}\left(20000 \mathrm{mg} \mathrm{L}^{-1}\right)$; 2) Gibberellic acid $\left(\mathrm{GA}_{3}\right) 50 \mathrm{mg} \mathrm{L}^{-1}$, 3) $\mathrm{GA}_{3} 100 \mathrm{mg} \mathrm{L}^{-1}$ 4) $\mathrm{GA}_{3}$ $200 \mathrm{mg} \mathrm{L}^{-1}$; 5) Stimulate $5 \mathrm{~mL} 0.5 \mathrm{~kg}^{-1}$ seeds; 6) Stimulate $10 \mathrm{~mL} 0.5 \mathrm{~kg}^{-1}$ seeds; 7) Water 24h; and 8) Control. The sowing was performed on polystyrene trays filled with land + commercial substrate. The five best treatments were selected to evaluate seedling growth. Plants aged 120

Recebido para publicação em 24/08/2009

Aceito para publicação em 14/12/2009

Rev. Bras. PI. Med., Botucatu, v.13, n.1, p.58-67, 2011. 
days from treatments $3,4,5,6$ and 8 were transplanted to plastic bags $(3 \mathrm{~kg})$ filled with land + sand + poultry manure (1:1:1 - v:v), kept under $50 \%$ shading and evaluated at $70,130,170$ and 210 days after transplanting. In general, light seeds had higher germinability and germination speed index (GSI) than the dark ones. However, the plants obtained from these seeds had lower growth than plants from dark seeds. In the second experiment, seeds were primed in the solutions: 1) PEG 6000 (-1.0 MPa); 2) PEG 6000 (-1.0 MPa) + $\mathrm{KNO}_{3}\left(20000 \mathrm{mg} \mathrm{L}^{-1}\right)(-1.0 \mathrm{MPa})$; 3) $\mathrm{KNO}_{3}$ (20000 $\left.\left.\mathrm{mg} \mathrm{L}^{-1}\right)(-1.0 \mathrm{MPa}) ; 4\right)$ Water; and 5) Deionized water, and incubated in a BOD chamber at 10 and $20^{\circ} \mathrm{C}$ for 0 (control), 6,12 and $24 \mathrm{~h}$. Then, seeds were dried at room temperature until reaching the matter presented before priming and incubated in a BOD chamber at $20-30^{\circ} \mathrm{C}$ with $8 \mathrm{~h}$ dark - $12 \mathrm{~h}$ light. The pregerminative treatments did not interfere with the vitality and vigor of seeds primed for up to $12 \mathrm{~h}$. There was no difference between 10 and $20^{\circ} \mathrm{C}$ for germinability $(60 \%)$ and GSI. However, the temperature of $10^{\circ} \mathrm{C}$ led seedlings to present higher fresh matter $(95.7 \mathrm{mg})$ and mean root $(3.2 \mathrm{~cm})$ and shoot $(2.6 \mathrm{~cm})$ length. Priming for $24 \mathrm{~h}$ decreased seed quality and seedling vigor.

Key words: biostimulant, gibberellin, priming, PEG $6000, \mathrm{KNO}_{3}$

\section{INTRODUÇÃO}

A área do bioma Cerrado no Brasil corresponde a aproximadamente 1,8 milhão de $\mathrm{km}^{2}$ (Aguiar et al., 2004), sendo que 13\% são ocupados com pastagens nativas, $23 \%$ com pastagens cultivadas, $5 \%$ com culturas agrícolas, $18 \%$ com outros tipos de uso e $41 \%$ correspondem às áreas não cultivadas (Sano et al., 2001). Apesar de possuir a maior diversidade de espécies quando comparado a outras savanas (Klink \& Machado, 2005), essas espécies são pouco conhecidas e estudadas e tem sofrido grande pressão antrópica, decorrente principalmente da atividade pecuária. Assim, com a expansão da fronteira agrícola, muitas espécies vegetais nativas de uso medicinal e, em decorrência, também do conhecimento a elas associado, vêm desaparecendo.

Jacaranda decurrens subsp. symmetrifoliolata - Bignoniaceae é um subarbusto xilopodífero da seção Monolobos, que ocorre exclusivamente na região sudoeste do estado de Mato Grosso do Sul (Farias \& Proença, 2003), em área de cerrado. É conhecida popularmente como carobinha-do-campo, carobinha ou caroba, e segundo indicações populares, o chá da raiz é utilizado como depurativo do sangue e cicatrizante de feridas uterinas e dos ovários (Sangalli, 2002). Dados sobre a utilização medicinal de J. decurrens foram relatados por Ferreira (1980) e Barros (1987) indicando que as folhas da espécie são utilizadas para problemas reumáticos e sífilis, e que as cascas combatem desinteria. $O$ fato das raízes da carobinha serem usadas em grande escala pela comunidade local tem contribuído para a ocorrência de pequeno número de plantas em seu habitat, o que poderá levá-la à extinção em curto espaço de tempo.

O conhecimento dos processos envolvidos na germinação de sementes de espécies nativas é de vital importância para a preservação das espécies ameaçadas e multiplicação dessas e das demais em programas de recomposição, regeneração e reflorestamento. Experimentos com Jacaranda decurrens subsp. symmetrifoliolata Farias \& Proença têm demonstrado que as sementes têm alta germinabilidade (Sangalli et al., 2004). Entretanto, embora a emissão da raiz primária tenha iniciado uma semana após a semeadura, a estabilização da emergência das plântulas só ocorreu a partir dos 42 dias após a semeadura, o que indica baixa velocidade de emergência da espécie quando comparada com outras Bignoniaceas, como por exemplo, as do gênero Tabebuia (Souza et al., 2005; Stockman et al., 2007; Pacheco et al., 2008), mas corrobora o observado para outras espécies de Jacaranda, como Jacaranda copaia D. Don (Abensur et al., 2007) e Jacaranda mimosifolia D. Don (Socolowski \& Takaki, 2004).

Como na produção de mudas é importante que as sementes germinem rápida e uniformemente, o que resulta em menor tempo no viveiro e mudas uniformes, diminuindo custos e facilitando o calendário dos plantios (Khan, 1992), tratamentos que acelerem e melhorem a germinação de sementes tornam-se essenciais. Para esse fim, e também para promover - crescimento das plantas jovens, vários pesquisadores (Santos \& Vieira, 2005; Garcia et al., 2006; Almeida \& Vieira, 2009) preconizam o uso de bioreguladores vegetais. Bioreguladores vegetais podem ser definidos como sendo substâncias sintetizadas, que aplicadas exogenamente possuem ações similares aos grupos de hormônios vegetais conhecidos (auxinas, giberelinas, citocininas, retardadores, inibidores e etileno). A mistura de dois ou mais bioreguladores vegetais ou de bioreguladores vegetais com outras substâncias (aminoácidos, nutrientes, vitaminas), é designada de bioestimulante ou estimulante vegetal (Castro \& Vieira, 2001).

Acredita-se que o bioestimulante, em função da composição, concentração e proporção das

Rev. Bras. Pl. Med., Botucatu, v.13, n.1, p.58-67, 2011. 
substâncias [0,005\% de ácido indolbutírico (auxina); $0,009 \%$ de cinetina (citocinina) e $0,005 \%$ de ácido giberélico (giberelina) - segundo o fabricante, Stoller do Brasil, 1998], pode incrementar o crescimento e desenvolvimento vegetal estimulando a divisão celular, bem como aumentar a absorção de água e nutrientes pelas plantas (Vieira \& Castro, 2002).

A técnica do osmocondicionamento (hidratação das sementes em soluções de baixo potencial osmótico) propicia maior uniformidade e sincronização da germinação, elevado índice de emergência e desenvolvimento das plântulas, mesmo em solos com baixos teores de umidade, e maior taxa de crescimento da parte aérea (Marcos Filho, 2005).

Para o condicionamento osmótico são utilizados agentes osmóticos inorgânicos como os sais cloreto de sódio $(\mathrm{NaCl})$, nitrato de potássio $\left(\mathrm{KNO}_{3}\right)$, sulfato de magnésio $\left(\mathrm{MgSO}_{4}\right)$ e agentes osmóticos orgânicos como o manitol, o glicerol, a sacarose, e o polietilenoglicol (PEG). O PEG é o agente osmótico mais comumente utilizado por não ser fitotóxico, não atravessar o sistema de membranas e não ser metabolizado pelas sementes, devido ao seu elevado peso molecular. É encontrado com pesos moleculares de 4000,6000, 8000 e 12000, sendo o de 6000 o mais utilizado (Somers et al., 1983). Segundo Haigh et al. (1986), a combinação de sais contendo nitrato e fosfato pode ser mais efetiva no condicionamento das sementes que as soluções puras de PEG 6000.

Visando melhorar o desempenho da germinação de sementes de Jacaranda decurrens subsp. symmetrifoliolata (carobinha) em condição de viveiro, o objetivo deste trabalho foi avaliar o efeito de tratamentos pré-germinativos na emergência das plantas e no crescimento inicial das mudas e, o desempenho germinativo das sementes submetidas osmocondicionamento em solução de $\mathrm{PEG}$ e $\mathrm{KNO}_{3}$.

\section{MATERIAL E MÉTODO}

Germinação e crescimento inicial da muda: No primeiro experimento, as sementes, obtidas a partir da abertura espontânea dos frutos maduros de carobinha, colhidos de matrizes cultivadas no Horto de Plantas Medicinais da Universidade Federal da Grande Dourados (UFGD), em Dourados - MS, em abril de 2007, foram separadas de acordo com a coloração creme - denominadas claras, e castanho - denominadas escuras. O experimento foi realizado em maio de 2007. As sementes de cada cor receberam oito tratamentos pré-germinativos: 1) Imersão em $\mathrm{KNO}_{3}\left(20000 \mathrm{mg} \mathrm{L}^{-1}\right)$; 2) Ácido giberélico $\mathrm{GA}_{3} 50 \mathrm{mg} \mathrm{L}^{-1}$; 3) $\mathrm{GA}_{3} 100 \mathrm{mg} \mathrm{L}^{-1}$;

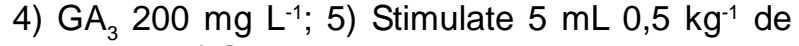

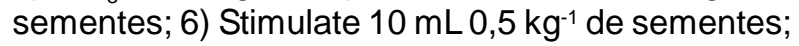

7) Água 8) Testemunha. As sementes foram depositadas em uma placa de petri e com auxílio de pipeta de pasteur o bioestimulante foi fornecido, pingando sobre a superfície de cada semente. Em seguida as sementes foram misturadas para que bioestimulante se espalhasse hormogeneamente sobre todas as sementes. As sementes foram deixadas durante uma hora em repouso para que 0 bioestimulante secasse.

A semeadura foi realizada em bandejas de 128 células de poliestireno expandido (Isopor ${ }^{\circledR}$ ) tendo como substrato terra (solo vermelho distroférrico de textura argilosa) + substrato comercial Plantimax ${ }^{\circledR}$ na proporção 1:1 (v:v). Foram utilizadas quatro repetições de 20 sementes, sendo disposta 1 semente por célula. As bandejas foram mantidas em casa de vegetação e irrigadas diariamente de forma a manter $70 \%$ da capacidade de campo.

Foi avaliado o número de plântulas emersas durante 40 dias e ao final desse período calculada a porcentagem de emergência (\% E), e o índice de velocidade de emergência (IVE), foi determinado pelo somatório do número de plântulas emergidas a cada contagem, dividido pelo número de dias decorridos entre a semeadura e a emergência, conforme Maguire (1962).

Aos 120 dias após a semeadura as plantas provenientes dos tratamentos 3) $\mathrm{GA}_{3} 100 \mathrm{mg} \mathrm{L}^{-1}$; 4)

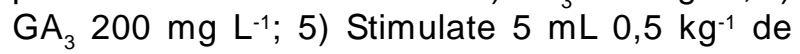
sementes; 6) Stimulate $10 \mathrm{~mL} 0,5 \mathrm{~kg}^{-1}$ de sementes e 8) Testemunha, foram transplantadas para embalagens plásticas com capacidade para três quilos preenchidas com substrato terra (solo vermelho distroférrico de textura argilosa) + areia + cama-de-frango na proporção 1:1:1 (v:v:v), e mantidas sob sombreamento de $50 \%$, obtido por meio do uso de tela preta de polietileno, conhecidas comercialmente por Sombrite ${ }^{\circledR}$. Foram utilizadas quatro repetições de oito mudas, as quais foram mantidas sob sombrite ${ }^{\circledR}$ de $50 \%$ e irrigadas diariamente por aspersão. Aos 70, 130, 170 e 210 dias após o transplante, foram realizadas medidas de altura, com auxílio de uma régua milimetrada até a inserção das folhas mais jovens no pecíolo e diâmetro de plantas com um paquímetro com precisão de $0,05 \mathrm{~mm}$ numa altura de $2 \mathrm{~cm}$ do solo.

Pré-condicionamento: No segundo experimento, as sementes de carobinha, independente da coloração, foram colocadas para a pré embebição em caixas de acrílico tipo gerbox $(11 \times 11 \times 3 \mathrm{~cm})$ sob duas folhas de papel filtro umedecidas com $15 \mathrm{~mL}$ das respectivas soluções-teste: 1) PEG $6000(-1,0 \mathrm{MPa})$; 2) PEG $6000(-1,0 \mathrm{MPa})+\mathrm{KNO}_{3}(-1,0 \mathrm{MPa})$; 3) $\mathrm{KNO}_{3}$ $(-1,0 \mathrm{MPa}) ; 4)$ Água e 5) Água deionizada. O cálculo para a concentração de PEG foi obtido de acordo com a equação de Michel \& Kaufmann (1973), descrito por Villela et al. (1991), e a concentração de $\mathrm{KNO}_{3}$ de acordo com a equação de Van't Hoff (citado por Hillel,

Rev. Bras. Pl. Med., Botucatu, v.13, n.1, p.58-67, 2011. 
1971). Para a mistura de $\mathrm{KNO}_{3}$ e PEG 6000 , foi usado $7,5 \mathrm{~mL}$ da solução de PEG e $7,5 \mathrm{~mL}$ de $\mathrm{KNO}_{3}$, desconsiderando-se a interação entre os dois produtos. Foram utilizados quatro repetições de 20 sementes.

As caixas foram cobertas com filme plástico para evitar a evaporação e incubadas em câmaras de germinação (BOD) reguladas a 10 e $20^{\circ} \mathrm{C}$ durante 0 (controle), 6, 12 e 24 horas, ambos com luz direta (24 horas). Após cada tempo de embebição, as sementes foram retiradas da BOD e permaneceram em condição de ambiente de laboratório sobre papel até atingirem a massa inicial apresentada antes do condicionamento. Em seguida, foram semeadas em caixas de acrílico tipo gerbox sobre duas folhas de papel filtro e, mantidas em BOD em temperatura alternada de $20-30^{\circ} \mathrm{C}$ em regime fotoperiódico de $8 \mathrm{~h}$ de escuro / $12 \mathrm{~h}$ de luz. Foram avaliados as seguintes variáveis-resposta: porcentagem de germinação (\%G) - considerando-se germinadas as sementes que emitiram a raiz primária, com protrusão de $\pm 2 \mathrm{~mm}$. As leituras foram realizadas em dias alternados, durante 35 dias; índice de velocidade de germinação (IVG) - calculado pelo somatório do número de plântulas normais germinadas $\left(G_{1}+G_{2}+G_{3}+\ldots G_{N}\right)$ a cada contagem, dividido pelo número de dias decorridos $\left(\mathrm{N}_{1}+\mathrm{N}_{2}+\mathrm{N}_{3}+\ldots \mathrm{N}_{\mathrm{N}}\right)$ entre a semeadura e a germinação, de acordo com a fórmula descrita por Maguire (1962): IVE $=\left[G_{1}+G_{2}+G_{3}+\ldots G_{N} / N_{1}+N_{2}\right.$ $+\mathrm{N}_{3}+\ldots \mathrm{N}_{\mathrm{N}}$; comprimento médio de raiz $(\mathrm{CMR}) \mathrm{e}$ de parte aérea (CMPA) - realizados ao final do teste de germinação (35 dias), selecionando-se três plântulas normais de cada repetição, as quais foram medidas com o auxílio de uma régua graduada em centímetros, sendo os resultados expressos em centímetros por plântula; massa fresca das plântulas (MF) - as plântulas anteriormente medidas foram pesadas em balança precisão de $0,001 \mathrm{~g}$, e os resultados foram transformados e expressos em $\mathrm{mg} /$ plântula; massa seca das plântulas (MS) - obtida pela secagem das plântulas, previamente pesadas para determinação da massa fresca, em estufa com circulação de ar forçada, regulada a $65^{\circ} \mathrm{C}$, até apresentar massa constante.

Procedimento estatístico: os dois experimentos foram realizados no delineamento inteiramente casualizado com quatro repetições. No primeiro, em esquema fatorial 2 (cores das sementes) $x 8$ (tratamentos pré-germinativos) para a emergência das plântulas e em esquema fatorial 2 (cores das sementes) $\times 5$ (tratamentos pré-germinativos) para análise de crescimento inicial da muda. No segundo experimento, os tratamentos consistiram de um fatorial 5 (tratamentos pré-condicionamento) $\times 2$ (temperaturas de condicionamento) $\times 4$ (tempos de incubação). Os dados foram submetidos à análise de variância, e as médias de tratamentos comparadas conforme a significância dos fatores e interações (teste de $F ; \alpha=0,05)$. Comparações entre os tratamentos pré-germinativos e as duas temperaturas foram realizadas pelo teste de Tukey $(\alpha=0,05)$, e entre épocas de avaliação e tempo de condicionamento por análise de regressão $(\alpha=0,05)$.

\section{RESULTADO E DISCUSSÃO}

\section{Emergência e crescimento inicial da muda}

Houve interação entre tratamentos prégerminativos e cor das sementes (Tabela 1). Sementes claras e escuras respondem de maneira diferente aos tratamentos pré-germinativos. As sementes escuras não apresentaram variação na emergência das plântulas em função dos tratamentos pré-germinativos, enquanto que as sementes claras responderam com maior porcentagem de germinação aos tratamentos com GA $3100 \mathrm{mg} \mathrm{L}^{-1}, \mathrm{GA}_{3} 200 \mathrm{mg} \mathrm{L}^{-1}$ e $\mathrm{KNO}_{3}\left(20000 \mathrm{mg} \mathrm{L}^{-1}\right)$.

Apesar de não terem apresentado diferença significativa entre os tratamentos na emergência das plântulas, as sementes de coloração escura apresentaram maior índice de velocidade de germinação para o tratamento com Stimulate ${ }^{\circledR} 5 \mathrm{~mL}$ $0,5 \mathrm{~kg}^{-1}$ de sementes e testemunha.

Sangalli et al. (2004) não observaram diferença significativa na porcentagem de germinação das sementes de Jacaranda decurrens subsp. symmetrifoliolata Farias \& Proença de coloração castanho-claro, castanho-médio e castanho-escuro, entretanto, observaram que as sementes claras germinaram mais rápido. Para esses autores, a ausência de diferença significativa na germinação das sementes em função da coloração das mesmas pode indicar que as mesmas não se encontram em diferentes estados fisiológicos de maturação, mas sim de característica intrínseca da espécie.

Entretanto, para algumas espécies a coloração das sementes pode estar associada à variação na permeabilidade do tegumento. Reis et al. (1985) observaram que sementes de Pterodon pubescens Benth (sucupira branca) de cor clara germinaram em maior proporção que as de cor escura e, atribuem tal fato à maior permeabilidade no tegumento, o que facilita as trocas gasosas das sementes claras em relação às escuras.

De modo semelhante, no presente estudo, as sementes claras responderam melhor aos tratamentos com giberelina e $\mathrm{KNO}_{3}$ do que as sementes escuras, apresentando maior porcentagem e índice de velocidade de emergência.

A heteromorfia em sementes já foi observada em espécies de várias famílias como Compositae, Cruciferae, Chenopodiaceae, Euphorbiaceae e Vochysiaceae (Godoy \& Felippe, 1992; Beneke et

Rev. Bras. Pl. Med., Botucatu, v.13, n.1, p.58-67, 2011. 
TABELA1. Porcentagem de emergência e índice de velocidade de emergência de plântulas de Jacaranda decurrens subsp. symmetrifoliolata. Dourados, 2007.

\begin{tabular}{|c|c|c|c|c|}
\hline \multirow[t]{2}{*}{ Tratamentos } & \multicolumn{2}{|c|}{ Emergência (\%) } & \multicolumn{2}{|c|}{$\begin{array}{c}\text { Índice de velocidade de } \\
\text { emergência }\end{array}$} \\
\hline & $\begin{array}{l}\text { Sementes } \\
\text { Claras }\end{array}$ & $\begin{array}{l}\text { Sementes } \\
\text { Escuras }\end{array}$ & $\begin{array}{l}\text { Sementes } \\
\text { Claras }\end{array}$ & $\begin{array}{l}\text { Sementes } \\
\text { Escuras }\end{array}$ \\
\hline Testemunha & $53,3 \mathrm{Ab}$ & $48,3 \mathrm{Aa}$ & $0,13 \mathrm{Ab}$ & $0,11 \mathrm{Bab}$ \\
\hline Stimulate ${ }^{\circledR} 5 \mathrm{~mL}_{0,5} \mathrm{~kg}^{-1}$ & $38,2 \mathrm{Ac}$ & $45,0 \mathrm{Aa}$ & $0,13 \mathrm{Ad}$ & $0,12 \mathrm{Aa}$ \\
\hline Stimulate ${ }^{\circledR} 10 \mathrm{~mL} 0,5 \mathrm{~kg}^{-1}$ & 56,7 Aab & $50,0 \mathrm{Aa}$ & $0,08 \quad A b$ & $0,10 \mathrm{Abc}$ \\
\hline $\mathrm{GA} 50 \mathrm{mg} \mathrm{L}^{-1}$ & $48,3 \quad A b c$ & $46,7 \mathrm{Aa}$ & $0,11 \quad A b c$ & $0,10 \mathrm{Bbc}$ \\
\hline GA $100 \mathrm{mg} \mathrm{L}^{-1}$ & 56,7 Aab & $38,3 \mathrm{Ba}$ & $0,17 \mathrm{Aa}$ & $0,08 \mathrm{Bc}$ \\
\hline GA $200 \mathrm{mg} \mathrm{L}^{-1}$ & $68,3 \mathrm{Aa}$ & $43,3 \mathrm{Ba}$ & $0,18 \mathrm{Aa}$ & $0,08 \mathrm{Bc}$ \\
\hline $\mathrm{KNO}_{3} 20000 \mathrm{mg} \mathrm{L}^{-1}$ & 56,7 Aab & $41,7 \mathrm{Ba}$ & $0,13 \mathrm{Ab}$ & $0,10 \mathrm{Bbc}$ \\
\hline Água & $46,7 \mathrm{Abc}$ & $41,7 \mathrm{Aa}$ & 0,10 Acd & $0,09 \mathrm{Abc}$ \\
\hline CV (\%) & \multicolumn{2}{|c|}{11,37} & \multicolumn{2}{|c|}{10,83} \\
\hline
\end{tabular}

Médias seguidas de mesma letra, maiúscula na linha e minúscula na coluna, não diferem entre si pelo teste de Tukey a 5\% de probabilidade.

al., 1993; Bewley \& Black, 1994; Venturi \& Randi, 1997). Entretanto, ainda necessita-se de mais informações sobre heteromorfia de sementes de Bignonicaecae. Alguns estudos com espécies arbóreas têm demonstrado que a qualidade fisiológica das sementes está associada à coloração do tegumento destas. Santos \& Aguiar (2005) observaram que as sementes estriadas de Sebastiania commersoniana (Baillon) Smith \& Downs (branquilho) apresentaram maior porcentagem e velocidade de germinação, seguidas das sementes escuras e posteriormente das claras. Qualea cordata Spreng. e Qualea grandiflora Mart. (pau-terra) apresentam sementes marrom-escuras e marromclaras, porém, apenas as do segundo tipo são viáveis (Felippe, 1990; Godoy \& Felippe, 1992).

As plantas provenientes de sementes claras que não receberam nenhum tipo de tratamento apresentaram maior altura que aquelas submetidas aos tratamentos pré-germinativos, entretanto, 0 diâmetro não variou significativamente entre os tratamentos, sendo menor nas plantas tratadas com $\mathrm{GA}_{3} 100 \mathrm{mg} \mathrm{L}^{-1}$ (Tabela 2). Plântulas provenientes das sementes escuras apresentaram maior altura em relação àquelas provenientes de sementes claras, a qual não variou entre a testemunha e os tratamentos com Stimulate ${ }^{\circledR}$. Entretanto, o diâmetro foi maior quando as sementes foram tratadas com Stimulate ${ }^{\circledR}$ $5 \mathrm{~mL} 0,5 \mathrm{~kg}^{-1}$ de sementes.

Não houve interação significativa dos tratamentos com os tempos de avaliação para a altura e diâmetro das mudas. As plantas apresentaram crescimento lento alcançando aos 210 dias após a semeadura apenas $8,77 \mathrm{~cm}$ de altura e 4,34 $\mathrm{m}$ de diâmetro (Figura 1). Assim, sugere-se que os tratamentos com Stimulate ${ }^{\circledR} 10 \mathrm{~mL} \mathrm{Kg}^{-1}$ e GA 3100 e

TABELA2. Altura e diâmetro das plantas Jacaranda decurrens subsp. symmetrifoliolata Farias \& Proença. Dourados, 2007.

\begin{tabular}{|c|c|c|c|c|c|}
\hline \multirow{3}{*}{$\begin{array}{l}\text { Tratamentos } \\
\text { Testemunha }\end{array}$} & \multicolumn{3}{|c|}{ Altura $(\mathrm{cm})$} & \multicolumn{2}{|c|}{ Diâmetro (mm) } \\
\hline & \multicolumn{2}{|c|}{ Clara } & \multirow{2}{*}{$\frac{\text { Escura }}{7,51 \mathrm{Aa}}$} & \multirow{2}{*}{$\frac{\text { Clara }}{2,72 \mathrm{Aa}}$} & \multirow{2}{*}{$\frac{\text { Escura }}{2,92 \mathrm{Ab}}$} \\
\hline & 8,16 & $\mathrm{Aa}$ & & & \\
\hline Stimulate ${ }^{\circledR} 5 \mathrm{~mL} 0,5 \mathrm{~kg}^{-1}$ & 7,00 & $\mathrm{Bb}$ & $7,92 \mathrm{Aa}$ & $2,79 \mathrm{Ba}$ & $3,50 \mathrm{Aa}$ \\
\hline Stimulate $^{\circledR} 10 \mathrm{~mL} 0,5 \mathrm{~kg}^{-1}$ & 6,51 & $\mathrm{Bb}$ & 7,85 Aa & $2,54 \mathrm{Aab}$ & $2,47 \mathrm{Ac}$ \\
\hline GA $100 \mathrm{mg} \mathrm{L}^{-1}$ & 6,76 & $A b$ & $6,41 \mathrm{Ab}$ & $2,27 \mathrm{Ab}$ & $2,45 \mathrm{Ac}$ \\
\hline GA $200 \mathrm{mg} \mathrm{L}^{-1}$ & 5,63 & $\mathrm{Bc}$ & $6,40 \mathrm{Ab}$ & $2,75 \mathrm{Aa}$ & 2,63 Ac \\
\hline CV (\%) & \multicolumn{3}{|c|}{15,35} & \multicolumn{2}{|c|}{21,44} \\
\hline
\end{tabular}

Médias seguidas de mesma letra maiúscula na linha e minúscula na coluna, pelo teste de Tukey a 5\% de probabilidade.

Rev. Bras. PI. Med., Botucatu, v.13, n.1, p.58-67, 2011. 
$200 \mathrm{mg} \mathrm{L}^{-1}$, embora propiciem incremento na emergência das plântulas e velocidade de emergência, não possuem efeito sobre o crescimento das mesmas.

Yuyama \& Silva Filho (2003) observaram para Myrciaria dubia H.B.K. Mc Vaugh (camu-camu) que as sementes de coloração marrom apresentaram menor porcentagem de germinação que as sementes verdes e mescladas, porém a altura e o diâmetro das plântulas não variaram entre as colorações, e os autores sugeriram que as variações tanto no tamanho quanto na coloração das sementes silvestres foi devida a variações de natureza genética e fisiológica, como fase de maturação diferente, as quais podem aumentar em função da procedência e do material genético.

\section{Pré-condicionamento}

Não houve diferença estatística entre as temperaturas de incubação para a porcentagem e velocidade de germinação das sementes e nem para a massa seca das plântulas (Tabela 3), enquanto que, para as características comprimento médio de raiz e da parte aérea e massa fresca, os maiores valores foram observados para o condicionamento a $10^{\circ} \mathrm{C}$.

Os tratamentos de condicionamento testados não diferiram entre si para nenhuma das características avaliadas (Tabela 3). Portanto, nas condições em que o experimento foi realizado, o osmocondicionamento não teve efeito no vigor e na viabilidade de sementes de carobinha, contrariando o esperado para esses tratamentos. Segundo Bradford (1986), o osmocondicionamento promove acúmulo de solutos no decorrer do processo, resultando em maior potencial de turgor celular durante a reidratação das sementes, o que resultaria na emergência da raiz primária em menor tempo.
Entretanto, alguns estudos mostraram que os efeitos do condicionamento osmótico são mais observados em sementes de baixo vigor (Silva et al., 2005) ou em sementes submetidas a condições adversas como a baixa disponibilidade hídrica, níveis elevados de salinidade e temperaturas subótima ou supra-ótima (Jeller \& Perez, 2003).

Para a porcentagem de germinação, índice de velocidade de germinação e comprimento médio da raiz foi observado interação significativa entre as temperaturas e o tempo de condicionamento. $\mathrm{O}$ osmocondicionamento das sementes a $10^{\circ} \mathrm{C}$ por 12 horas proporcionou aumento na porcentagem de germinação, porém quando o condicionamento foi realizado por 24 horas, observou-se redução da germinação. O osmocondicionamento a $20^{\circ} \mathrm{C}$ foi prejudicial à germinação das sementes, sendo observada redução na porcentagem de germinação das sementes à medida que aumentou o período de condicionamento das mesmas (Figura 2a).

Tonin et al. (2005) também observaram que o condicionamento de sementes de (amendoim do campo) (Pterogyne nitens Tul.) a $10^{\circ} \mathrm{C}$ foi mais eficiente que a $27^{\circ} \mathrm{C}$, apresentando maior porcentagem e velocidade de germinação em relação ao condicionamento a $27^{\circ} \mathrm{C}$. Segundo esses autores a temperatura de $10^{\circ} \mathrm{C}$, ao permitir embebição mais lenta, provavelmente possibilitou a garantia de melhor integridade das membranas das sementes dessa espécie. Entretanto, Wanli et al. (2001), avaliando o efeito do pré-condicionamento em sementes de Peltophorun dubium (Spreng.) Taub. (canafístula), concluíram que o pré-condicionamento em água e em PEG (-1MPa) tanto a $10^{\circ} \mathrm{C}$ como a $27^{\circ} \mathrm{C}$ não aumentaram o vigor e nem a viabilidade das sementes.

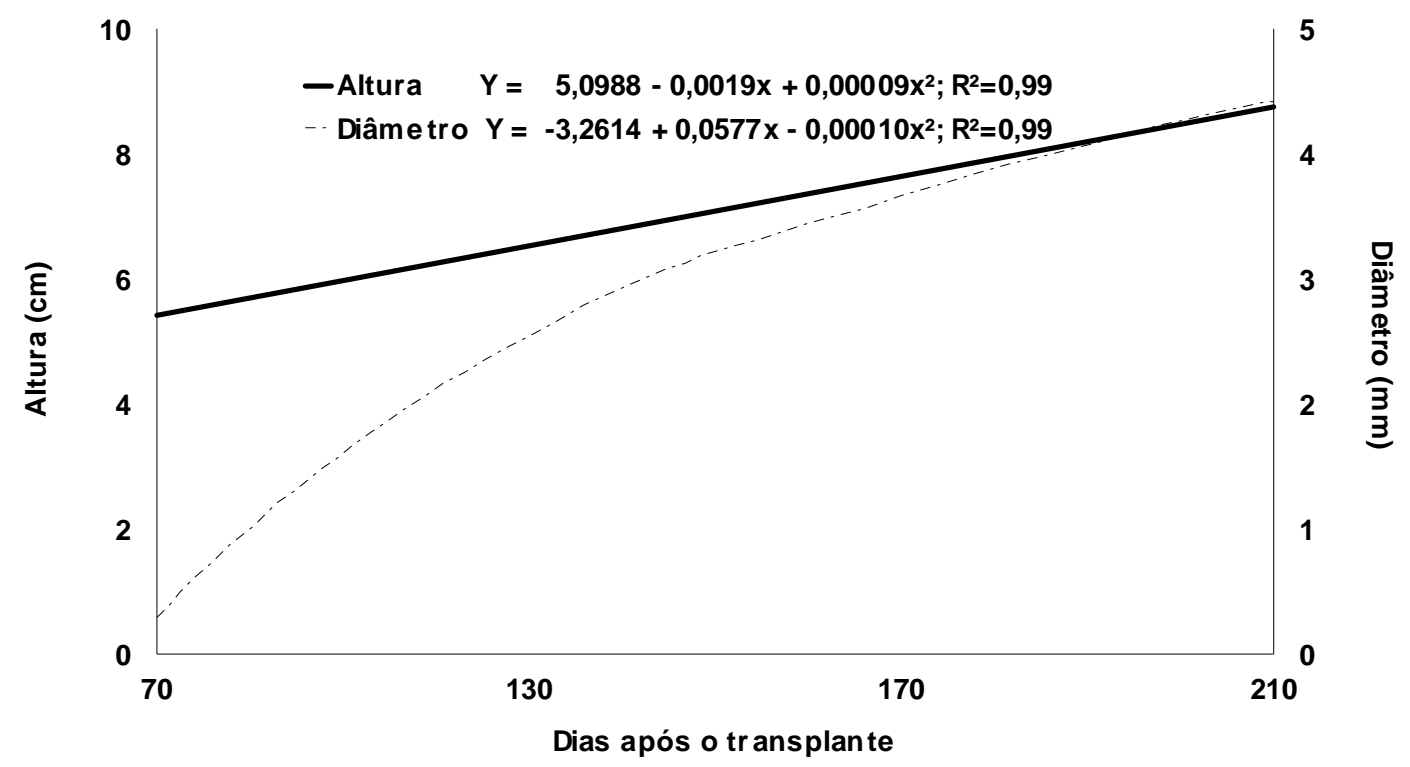

FIGURA 1. Altura e diâmetro das plantas Jacaranda decurrens subsp. symmetrifoliolata Farias \& Proença. Dourados, 2007. 
TABELA 3. Porcentagem de germinação (G), índice de velocidade de germinação (IVG), comprimento médio de raiz (CMR) e de parte aérea (CMPA), massa fresca (MF) e seca (MS) de plântulas de Jacaranda decurrens symmetrifoliolata Farias \& Proença, submetidas a pré-tratamentos de condicionamento fisiológico, em duas temperaturas. Dourados, 2007.

\begin{tabular}{lcccccc}
\hline & $\begin{array}{c}\mathrm{G} \\
(\%)\end{array}$ & $\begin{array}{c}\mathrm{IVG} \\
\left(\mathrm{dias}^{-1}\right)\end{array}$ & $\begin{array}{c}\mathrm{CMR} \\
(\mathrm{cm})\end{array}$ & $\begin{array}{c}\mathrm{CMPA} \\
(\mathrm{cm})\end{array}$ & $\begin{array}{c}\mathrm{MF} \\
(\mathrm{mg})\end{array}$ & $\begin{array}{c}\mathrm{MS} \\
(\mathrm{mg})\end{array}$ \\
\hline $10^{\circ} \mathrm{C}$ & $60,3 \mathrm{a}$ & $0,628 \mathrm{a}$ & $3,2 \mathrm{a}$ & $2,6 \mathrm{a}$ & $95,69 \mathrm{a}$ & $44,77 \mathrm{a}$ \\
$20^{\circ} \mathrm{C}$ & $60,0 \mathrm{a}$ & $0,610 \mathrm{a}$ & $2,8 \mathrm{~b}$ & $2,1 \mathrm{~b}$ & $84,90 \mathrm{~b}$ & $42,74 \mathrm{a}$ \\
$\mathrm{PEG}$ & $63,3 \mathrm{a}$ & $0,654 \mathrm{a}$ & $3,0 \mathrm{a}$ & $2,5 \mathrm{a}$ & $94,47 \mathrm{a}$ & $44,62 \mathrm{a}$ \\
$\mathrm{PEG}+\mathrm{KNO}_{3}$ & $61,5 \mathrm{a}$ & $0,644 \mathrm{a}$ & $3,2 \mathrm{a}$ & $2,5 \mathrm{a}$ & $91,62 \mathrm{a}$ & $44,15 \mathrm{a}$ \\
$\mathrm{KNO}_{3}$ & $60,2 \mathrm{a}$ & $0,617 \mathrm{a}$ & $2,8 \mathrm{a}$ & $2,3 \mathrm{a}$ & $88,78 \mathrm{a}$ & $43,47 \mathrm{a}$ \\
Água torneira & $60,0 \mathrm{a}$ & $0,620 \mathrm{a}$ & $3,2 \mathrm{a}$ & $2,4 \mathrm{a}$ & $94,06 \mathrm{a}$ & $45,78 \mathrm{a}$ \\
Água deionizada & $58,3 \mathrm{a}$ & $0,561 \mathrm{a}$ & $2,8 \mathrm{a}$ & $2,1 \mathrm{a}$ & $82,53 \mathrm{a}$ & $40,75 \mathrm{a}$ \\
\hline CV $(\%)$ & 13,4 & 18,9 & 20,4 & 20,5 & 19,4 & 21,1 \\
\hline
\end{tabular}

Médias seguidas de mesma letra, na coluna, são estatisticamente iguais entre si pelo teste de Tukey a $5 \%$ de probabilidade.

No condicionamento das sementes em baixas temperaturas, a embebição é lenta e há tempo suficiente para que as membranas das células, que são compostas por camada dupla de fosfolipídeos e que ao se desidratarem passam de estado fluído para estado de gel, voltem ao estado cristalino líquido, sem ocorrer danos celulares e lixiviação (Castro \& Hilhorst, 2004).

De maneira semelhante ao observado para a porcentagem de germinação, observou-se maior velocidade de germinação das sementes submetidas ao condicionamento na temperatura de $10^{\circ} \mathrm{C}$ por 12 horas, enquanto a velocidade de germinação das sementes submetidas ao condicionamento a $20^{\circ} \mathrm{C}$ reduziu com o aumento do período de condicionamento (Figura 2b). Bonome et al. (2006) também observaram redução na velocidade de protrusão radicular em sementes de braquiária (Brachiaria brizantha cv. Marandu) quando o período de condicionamento das sementes foi elevado de 12 para 24 horas.

Borges et al. (1994) observaram que a embebição prévia de sementes de quaresminha (Miconia condellana Trian) em soluções de PEG 6000 aumentou a velocidade de germinação, e a resposta foi dependente do tempo de condicionamento. $\mathrm{O}$ condicionamento tanto em água como em polietilenoglicol ou em $\mathrm{NaCl}$ isolados ou seguidos de imersão em giberelina não influenciou o percentual de germinação das sementes de Triplaris americana L. (pau-formiga). Entretanto, o condicionamento em água por sete dias a $25^{\circ} \mathrm{C}$ e o condicionamento em solução de polietilenoglicol + ácido giberélico proporcionaram maior velocidade de germinação das sementes (Mendonça et al., 2005).

A vantagem da maior velocidade de germinação proporcionada pelo osmocondicionamento deve ser entendida como a possibilidade de menor exposição das sementes às diversas fontes de estresse que normalmente ocorrem no solo, como variações extremas de temperatura, disponibilidade hídrica, ataque de insetos e/ou microrganismos, entre outras. Por outro lado, e como conseqüência direta da mais rápida emergência, o cultivo é beneficiado por um grau de uniformidade de desenvolvimento que, em condições normais, não ocorre (Trigo et al., 1999).

O comprimento médio de raiz de plântulas provenientes de sementes osmocondicionadas a $10^{\circ} \mathrm{C}$ não foi influenciado pelo período de condicionamento, apresentando, em média, $3,2 \mathrm{~cm}$. Para o condicionamento a $20^{\circ} \mathrm{C}$ observou-se maior comprimento de raiz quando as sementes foram condicionadas por 12 horas (Figura 2c). Plântulas provenientes de sementes osmocondicionadas em solução de PEG e PEG + $\mathrm{KNO}_{3}$ não apresentaram variação no comprimento de raiz em função do tempo de condicionamento, enquanto que para as plântulas provenientes dos demais tratamentos, os maiores comprimentos de raiz foram observados para aquelas condicionadas durante 12 horas (Figura 2d).

Para o comprimento médio de parte aérea e massa seca das plântulas não houve interação entre as temperaturas e períodos de condicionamento. Entretanto, o fator período de condicionamento foi significativo. Para ambas as características-resposta supracitadas, observou-se redução nos valores com o aumento do tempo de condicionamento (Figuras 2e e 2f).

Estudos de osmocondicionamento de sementes de espécies nativas ainda são poucos e os que existem, limitam-se a avaliação da porcentagem e velocidade germinação das sementes, 
$-\square-10$ C $\hat{y}=64.3590+0.9201 x-0.067 x^{2} \cdot R^{2}=0.68$

-20 C $\hat{y}=71.6400-1.1062 x \cdot R^{2}=0.84$

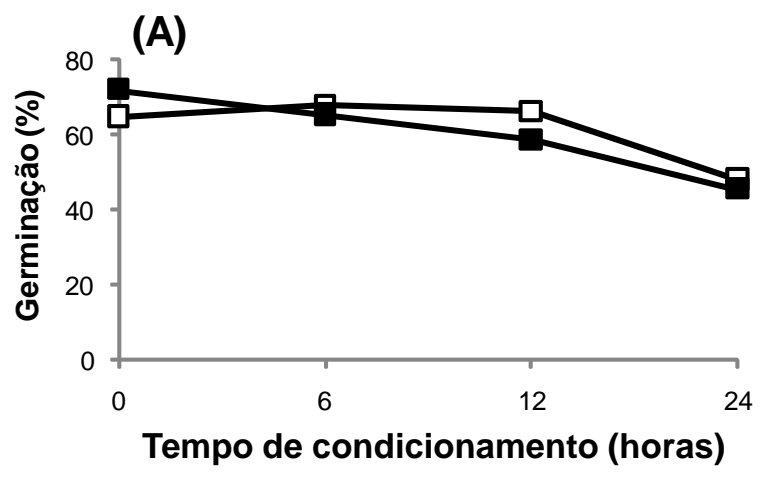

$-\square-10 C \hat{y}=\bar{y}=3.2$

-20 C $\hat{y}=2.5000-0.2825 x+0.0489 x^{2} \cdot R^{2}=1.0$

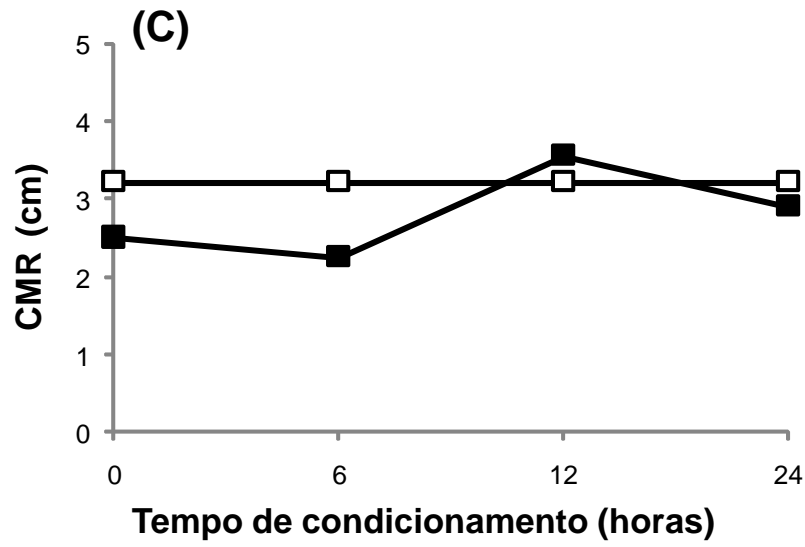

$\leftarrow \hat{y}=2.6900-0.031 x \cdot R^{2}=0.97$

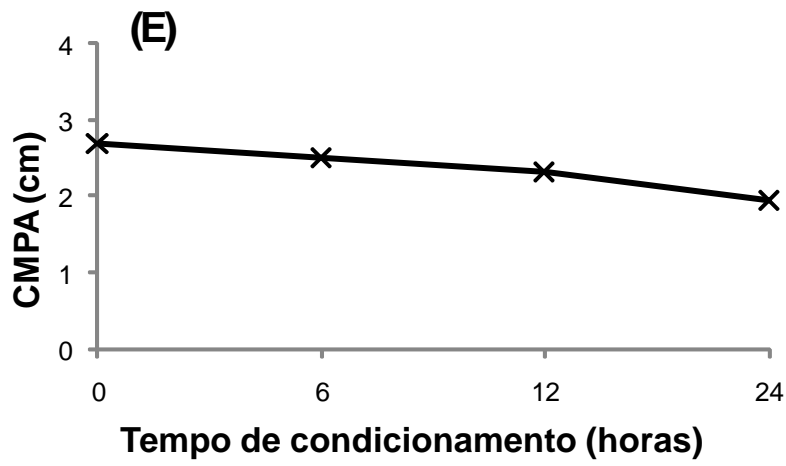

$-\square-10$ C $\hat{y}=0.6027+0.0257 x-0.0013 x^{2} \cdot R^{2}=0.52$

-20 C $\hat{y}=0.6808-0.0067 x \cdot R^{2}=0.54$

(B)

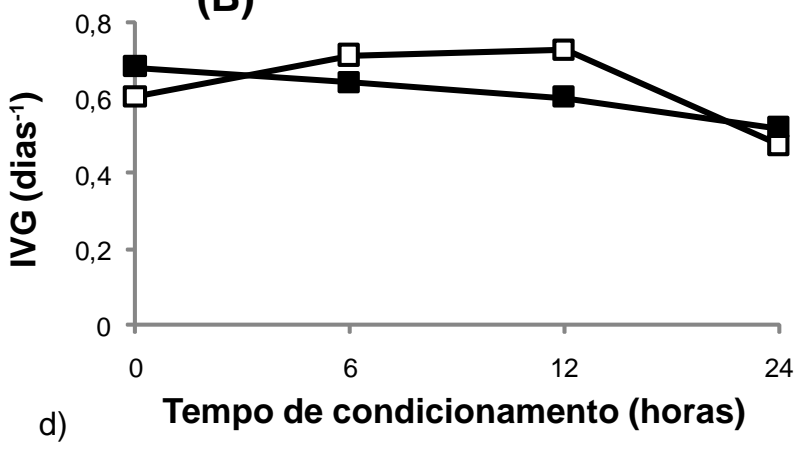

$\leadsto$ PEG $\hat{y}=\bar{y}=3.0$

$P E G+\mathrm{KNO}_{3} \quad \hat{\mathrm{y}}=\overline{\mathrm{y}}=3.2$

$-\mathrm{KNO}_{3} \quad \hat{\mathrm{y}}=2.8750-0.4496 \mathrm{x}+0.0612 \mathrm{x}^{2}-0.001760 \mathrm{x}^{3} . \mathrm{R}^{2}=1.0$

$\rightarrow$ Água $\hat{y}=2.8750-0.4427 x+0.0733 x^{2}-0.002242 x^{3} \cdot R^{2}=1.0$

- - Testemunha $\hat{y}=2.8648+0.1383 x-0.0081 x^{2} \cdot R^{2}=0.99$

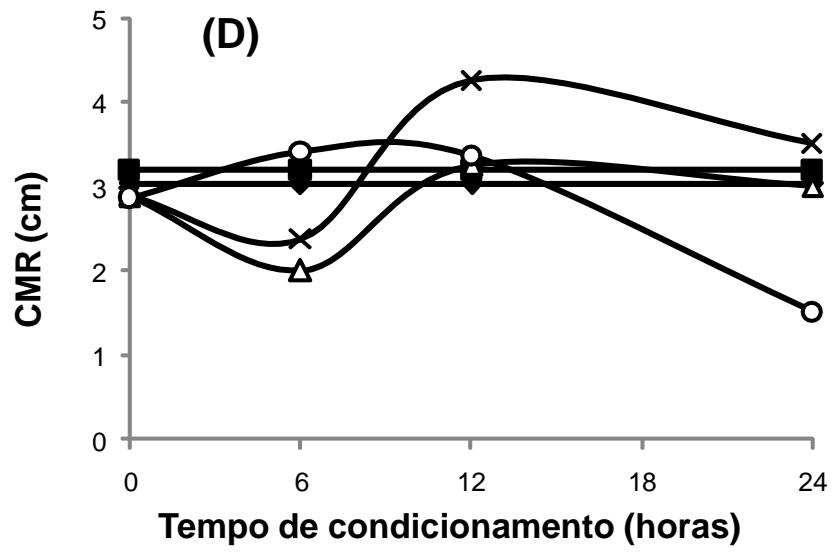

$\nVdash-\hat{y}=55.7286-2.1061 x+0.0537 x^{2} ; R^{2}=0.91$

$(\mathrm{F})$

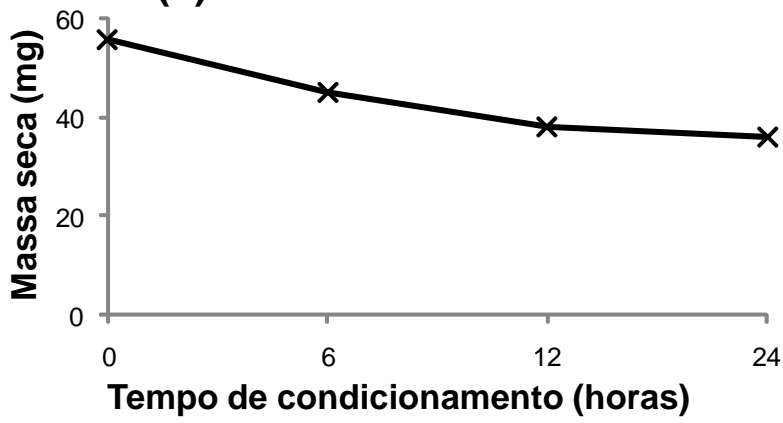

FIGURA 2. (A) Porcentagem de germinação, (B) índice de velocidade de germinação (IVG), (C,D) comprimento médio de raiz (CMR), (E) comprimento médio de parte aérea (CMPA) e (F) massa seca de plântulas de Jacaranda decurrens subsp. symmetrifoliolata Farias \& Proença. 
sem fazer referência ao desenvolvimento das plântulas. Entretanto, para sementes de soja, há relatos de que o condicionamento osmótico propiciou maior crescimento das plântulas e maiores valores de matéria seca (Armstrong \& McDonald, 1992; Bracini et al., 1999). Segundo Dell Áquila \& Taranto (1986), o osmocondicionamento permite a ocorrência de processos metabólicos necessários ao começo da divisão e expansão celular, induz a aumento dos processos de síntese, o que leva a balanço metabólico mais favorável à germinação e ao crescimento das plântulas.

Baseado nos resultados observou-se que as sementes claras responderam melhor aos tratamentos pré-germinativos, apresentando maior emergência de plântulas e índice de velocidade de emergência em relação às sementes escuras. Entretanto, as plantas provenientes dessas sementes apresentaram menor crescimento do que as plantas provenientes das sementes escuras.

Observou-se também que as sementes de carobinha comportaram-se de maneira indiferente aos tipos de tratamentos de osmocondicionamento e, quando esse foi realizado por 24 horas foi prejudicial à germinação das sementes e desenvolvimento das plântulas. As temperaturas de osmocondicionamento não diferiram para porcentagem e índice de velocidade de germinação, entretanto, o osmocondicionamento a $10^{\circ} \mathrm{C}$ proporcionou melhor condição para 0 desenvolvimento das plântulas. $O$ osmocondicionamento proporcionou maior porcentagem e índice de velocidade de germinação comparado aos tratamentos com bioestimulante.

\section{AGRADECIMENTO}

À FUNDECT pelo apoio financeiro e à CAPES pela concessão de bolsa à primeira autora

\section{REFERÊNCIA}

ABENSUR, F.O. et al.Tecnologia de sementes e morfologia da germinação de Jacaranda copaia D. Don (Bignoniaceae). Revista Brasileira de Biociências, v.5, supl.2, p.60-2, 2007.

ALMEIDA, A.Q.; VIEIRA, E.L. Efeito do stimulate ${ }^{\circledR}$ na produção de Nicotiana tabacum tipo Brasil-Bahia. Magistra, v.21, n.1, p.18-22, 2009.

AGUIAR, L.M.S.; MACHADO, R.B.; MARINHO-FILHO, J. A diversidade biológica do Cerrado. In: AGUIAR, L.M.; CAMARGO, A.J.A. (Orgs.). Cerrado: ecologia e caracterização. Planaltina: Embrapa Cerrados; Brasília: Embrapa Informação Tecnológica, 2004. p.17-40.

ARMSTRONG, H.; McDONALDS, M.B. Effects of osmoconditioning on water uptake and electrical conductivity in soybeans seeds. Seed Science and Technology, v.20, n.2, p.391-400, 1992.
BARROS, M.A.G.E. Flora medicinal do Distrito Federal. Brasil Florestal, v.12, p.35-45, 1987.

BENEKE, K. et al. Fruit polymorphism in ephemeral species of Namaqualand: III. Germination differences between the polymorphic diaspores. Journal of Arid Environments, v.24, p.333- 44, 1993.

BEWLEY, J.D.; BLACK, M. Seeds: physiology of development and germination. 2.ed. Nova York: Plenum Press, 1994. 445p.

BONOME, L.T.S. et al. Efeito do condicionamento osmótico em sementes de Brachiaria brizantha cv. Marandu. Ciência e Agrotecnologia, v.30, n.3, p.422-8, 2006.

BORGES, E.E.L.; SILVA, L.F.; BORGES, R.C.G. Avaliação do omocondicionamento na germinação de sementes de quaresminha (Miconia condolleana Trian.). Revista Brasileira de Sementes, v.16, p.90-4, 1994.

BRACINI, A.L. et al. Avaliação da qualidade fisiológica de sementes de soja, após o processo de hidrataçãodesidratação e envelhecimento acelerado. Pesquisa Agropecuária Brasileira, v.34, n.6, p.1053-66, 1999. BRADFORD, K.J. Manipulation of seed water relations via osmotic priming to improve germination under stress conditions. Hort Science, v.21, n.5, p.1105-12, 1986.

CASTRO, R.D.; HILHORST, H.W.M. Embebição e reativação do metabolismo. In: FERREIRA, A.G.; BORGHETTI, F. (Orgs.). Germinação: do básico do aplicado. Porto Alegre: Artmed, 2004. p.149-62.

CASTRO, P.R.C.; VIEIRA, E.L. Aplicação de reguladores vegetais na agricultura tropical. Guaíba: Agropecuária, 2001. 132p.

DELL ÁQUILA, A.; TARANTO, G. Cell division and DNA synthesis during osmopriming treatment and following germination on aged wheat embryos. Seed Science and Technology, v.14, n.2, p.333-41, 1986.

FARIAS, R.; PROENÇA, C. Jacaranda decurrens subsp. symmetrifoliolata Farias \& Proença (Bignoniaceae), novo táxon para o bioma cerrado. Boletim do Herbarium Bradeanum, v.11, p.5-9, 2003.

FELIPPE, G.M. Qualea grandiflora: the seeds and its germination. Revista Brasileira de Botânica, v.13, n.1, p.33-7, 1990.

FERREIRA, C.A.G. Recuperação de áreas degradadas. Informe Agropecuário, v.21, n.202, p.127-30, 1980.

GARCIA, A.S. et al. Efeito de reguladores vegetais na germinação e desenvolvimento da semente Strelitzia reginae. Thesis, v.1, p.5, 2006.

GODOY, S.M.; FELIPPE, G.M. Qualea cordata: a semente e sua germinação. Revista Brasileira de Botânica, v.15, n.1, p.17-21, 1992.

HAIGH, A.M. et al. Field emergence of tomato, carrot and onion seeds primed in aerated salt solution. Journal of Amercian Society of Horticultural Sciences, v.111, p.660-5, 1986.

HILLEL, D. Soil and water: physical principles and process. New York: Academic Press, 1971. 288p.

JELLER, H.; PEREZ, S.C.J.G.A. Condicionamento osmótico na germinação de sementes de cássia-donordeste sob estresse hídrico, térmico e salino. Pesquisa Agropecuária Brasileira, v.38, n.9, p.1025-34, 
2003.

KHAN, A.A. Preplant physiological seed conditioning. Horticultural Review, v.13, p.131-81, 1992.

KLINK, C.A.; MACHADO, R.B. A conservação do Cerrado brasileiro. Megadiversidade, v.1, n.1, p.147-55, 2005.

MAGUIRE, J.D. Speed of germination-aid in selection and evaluation for seedling emergence and vigor. Crop Science, v.2, n.1, p.176-7, 1962.

MARCOS FILHO, J. Fisiologia de sementes de plantas cultivadas. Piracicaba: Fealq, 2005. 495p.

MENDONÇA, A.V.R. et al. Efeito da hidratação e do condicionamento osmótico em sementes de pauformiga. Revista Brasileira de Sementes, v.27, n.2, p.1116, 2005.

PACHECO, M.V et al. Germinação de sementes e crescimento inicial de plântulas de Tabebuia aurea (Siva Manso) Beth. \& Hook. Ex S. Moore. Ciência Florestal, v.18, n.2, p.143-50, 2008.

REIS, G.G.; DRUNE, A.; RENA, A.B. Estudos sobre a dormência de sementes de sucupira(Pterodon pubescens Benth): tratamento para superação da dormência. Revista Árvore, v.9, n.1, p.49-57, 1985.

SANGALLI, A. Levantamento e caracterização de plantas nativas com propriedades medicinais em fragmentos florestais e de Cerrado de Dourados-MS, numa visão etnobotânica. Acta Horticulturae, n. 569, p. 173-84, 2002. SANGALLI, A.; SCALON, S.P.Q.; VIEIRA, M.C. Cor, temperatura e pré-embebição na germinação de sementes de carobinha (Jacaranda decurrens subsp. symmetrifoliolata Farias \& Proença) Bignoniaceae. Revista Brasileira de Plantas Medicinais, v.7, p.79-85, 2004.

SANO, E.E.; JESUS, E.T.; BEZERRA, H.S. Uso de um sistema de informações geográficas para quantificação de áreas remanescentes do Cerrado. Planaltina: Embrapa Cerrados, 2001. 4p. (Embrapa Cerrados. Comunicado Técnico, 62).

SANTOS, S.R.G.; AGUIAR, I.B. Efeito da temperatura na germinação de sementes de Sebastiania commersoniana (Baillon) Smith \& Downs separadas pela coloração do tegumento. Scientia Forestalis, n.69, p.77-83, 2005.

SANTOS, C.M.G.; VIEIRA, E.L.V. Efeito de bioestimulante na germinação de sementes, vigor de plântulas e crescimento inicial do algodoeiro. Magistra, v.17, n.3, p.124-30, 2005.

SOCOLOWSKI, F.; TAKAKI, M. Germination of Jacaranda mimosifolia (D. Don - Bignoniaceae) seeds: Effects of light, temperature and water stress. Brazilian Archives of Biology and Technology, v.47, n.5, p.785-92, 2004. SILVA, L.M.M. et al. Estresse hídrico e condicionamento osmótico na qualidade fisiológica de sementes de faveleira Cnidoscolus juercifolius. Revista Brasileira de Engenharia Agrícola e Ambiental, v.9, n.1, p.66-72, 2005. SOMERS, D.A.; ULLRICH, S.E.; RAMSAY, M.F. Sunflower germination under simulated drought stress. Agronomy Journal, v.75, n.2, p.570-2, 1983.

SOUZA, V.C.; BRUNO, R. L.A.; ANDRADE, L.A. Vigor de sementes armazenadas de ipê-amarelo Tabebuia serratifolia (Vahl.) Nich. Revista Árvore, v.29, n.6, p.83341, 2005.

STOCKMAN, A.L. et al. Sementes de ipê-branco (Tabebuia roseo-alba (Ridl.) Sand. - Bignoniaceae): temperatura e substrato para o teste de germinação. Revista Brasileira de Sementes, v.29, n.3, p.139-43, 2007. STOLLER DO BRASIL. Stimulate Mo em hortaliças: informativo técnico. Stoller do Brasil. Divisão Arbore. 1998. TONIN, G.A. et al. Influência da temperatura de condicionamento osmótico na viabilidade e no vigor de sementes de Pterogyne nitens Tul. Revista Brasileira de Sementes, v.27, p.35-43, 2005.

TRIGO, M.F.O.O.; NEDEL, J.L.; TRIGO, L.F.N. Condicionamento osmótico em sementes de cebola: I. Efeitos sobre a germinação. Scientia Agricola, v.56, n.4, p.1059-67, 1999.

YUYAMA, K.; SILVA FILHO, D.F. Influência do tamanho e da coloração da semente na emergência de plântulas de camu-camu. Revista de Ciências Agrárias, v.39, p.155-62, 2003.

VENTURI, S.; RANDI, A.M. Influência da coloração das sementes na germinação de Phyllanthus tenellus Roxb. e Phyllanthus niruri L. (Euphorbiaceae). Acta Botanica Brasílica, v.11, n.1, p.87-94, 1997.

VIEIRA, E.L.; CASTRO, P.R.C. Ação de Stimulate no desenvolvimento inicial de plantas de algodoeiro (Gossypium hirsutum L.). Piracicaba: USP, Departamento de Ciências Biológicas, 2002. 3p. (Apostila).

VILLELA, F.A.; DONI-FILHO, L.; SEQUEIRA, E.L. Tabela de potenciais osmóticos em função da concentração de polietilenoglicol 6000 e da temperatura. Pesquisa Agropecuária Brasileira, v.26, p.1957-68, 1991.

WANLI, Z.; LEIHONG, L.; PEREZ, S.C.J.G.A. Pré condicionamento e seus efeitos em sementes de canafístula (Peltophorum dubium (Spreng) Taub). Revista Brasileira de Sementes, v.23, n.1, p.146-53, 2001.

Rev. Bras. PI. Med., Botucatu, v.13, n.1, p.58-67, 2011. 